\title{
ESTUDO DA ESTABILIDADE DO EXTRATO HIDROSSOLÚVEL “LEITE” DE BABAÇU (Orbygnia speciosa) PASTEURIZADO E ARMAZENADO SOB REFRIGERAÇÃO ${ }^{1}$
}

\author{
BRUNA LORENA AGUIAR CARNEIRO ${ }^{2}$, AROLDO ARÉVALO-PINEDO ${ }^{3}$, LAURA SCARTAZZINI ${ }^{4}$ \\ ABRAHAM DAMIAN GIRALDO-ZUNIGA², ROSALINDA ARÉVALO PINEDO²
}

RESUMO- Este trabalho teve como objetivo desenvolver a tecnologia de conservação do extrato hidrossolúvel de babaçu baseado na pasteurização e na refrigeração. O extrato hidrossolúvel extraído da amêndoa de babaçu, também conhecido no Norte e Nordeste do Brasil como "leite" de babaçu, é um líquido branco ou levemente amarelado, de sabor e aroma muito semelhantes ao do leite de coco comum. O leite de babaçu extraído através de prensagem foi peneirado, pré-aquecido, adicionado de estabilizante carboximetilcelulose e homogeneizado em liquificador industrial. O leite de babaçu homogeneizado foi dividido em duas porções, adicionando-se em uma destas $0,4 \%$ de metabissulfito de sódio, $0,4 \%$ de sorbato de potássio e $0,01 \%$ de ácido cítrico, e outra foi mantida sem conservantes (controle). Os leites sem e com conservantes foram envasados em garrafas de vidro e pasteurizados em banho-maria à temperatura de $90^{\circ} \mathrm{C}$ por 30 minutos, resfriados à temperatura ambiente e mantidos sob refrigeração a $5^{\circ} \mathrm{C}$, durante 60 dias. As formulações foram caracterizadas físico-quimicamente quanto ao $\mathrm{pH}$, sólidos solúveis ( $\left.{ }^{\circ} \mathrm{Brix}\right)$, acidez, açúcares totais e redutores, umidade, cinzas, gorduras e proteínas. Durante o armazenamento, a cada 15 dias, foram realizadas análises físico-químicas ( $\mathrm{pH}$, acidez total titulável e atividade de água), colorimétricas e microbiológicas. Os resultados mostram que houve pouca variação nos parâmetros físico-químicos; entretanto, microbiologicamente o leite de babaçu apresentou crescimento microbiano a partir dos 30 dias, atingindo valores elevados, acima dos padrões microbiológicos estabelecidos pela legislação, após os 60 dias de armazenamento.

Termos para indexação: babaçu, conservação, extrato hidrossolúvel, refrigeração.

\section{STABILITY OF BABASSU NUT MILK PASTEURIZED AND STORAGE UNDER REFRIGERATION}

\begin{abstract}
New products can be developed using the babassu nut, as the water soluble extract called babassu nut milk that has a good market potential and high acceptability as ingredients in Brazilian cuisine in ice cream, cakes, drinks, etc. especially in northern and northeastern Brazil. The babassu nut milk is currently produced in a handmade way without the application of any technology of conservation and hygiene. In this context, this work aimed to studying the stability physicochemical and microbiological of babassu nut milk pasteurized and storage under refrigeration. The results show that there has been little variation of physical and chemical parameters of product with and without aditivies, however, microbiologically babassu nut milk showed microbial growth from 30 days, reaching high values, above the microbiological standards laid down by the law, after the 60 days of storage.
\end{abstract}

Index terms: babassu, conservation, soluble extract, refrigeration.

\footnotetext{
1(Trabalho 334-13). Recebido em: 16-09-2013. Aceito para publicação em: 13-02-2014.

${ }^{2}$ Professores Curso de Engenharia de Alimentos, Universidade Federal do Tocantins, UFT, Av. NS 15, ALCNO 14, 7123-360, PalmasTO, Brasil. E-mail: aroldo@uft.edu.br. Autor para correspondência

${ }^{3}$ Aluno do Curso de Engenharia de Alimentos, Universidade Federal do Tocantins, UFT, Av. NS 15, ALCNO 14, 7123-360, PalmasTO, Brasil. E-mail:

${ }^{4}$ Professora do Curso de Engenharia de Alimentos, Universidade Federal da Grande dourados, 79825-070, Dourados-MS, Brasil
}

Rev. Bras. Frutic., Jaboticabal - SP, v. 36, n. 1, p.232-236, Março 2014 


\section{INTRODUÇÃO}

O Babaçu é uma palmeira brasileira de grande porte (até $20 \mathrm{~m}$ ), de tronco cilíndrico e copa em formato de taça. $\mathrm{O}$ fruto é uma drupa com elevado número de frutos por cacho, sendo estes em número de 4 (hábitat), que variam de 15 a 25 (TEIXEIRA, 2008). A composição física do fruto indica quatro partes aproveitáveis: epicarpo $(11 \%)$, mesocarpo (23\%), endocarpo (59\%) e amêndoa (7\%). A amêndoa corresponde de 6 a $8 \%$ do peso do coco integral. As amêndoas estão envoltas por um tegumento castanho e são separadas umas das outras por paredes divisórias. Pesam, em média, de 3 a 4 g, e contêm entre 60 e $68 \%$ de óleo, podendo alcançar $72 \%$ em condições mais favoráveis de crescimento da palmeira. As amêndoas secas ao ar contêm aproximadamente $4 \%$ de umidade e têm sido o componente do fruto mais intensivamente utilizado (SOLER et al., 2007). Os babaçus brasileiros concentram-se nas regiões Nordeste, Norte e Centro-Oeste, merecendo maior destaque a região Nordeste, que detém, atualmente, a maior produção de amêndoas e a maior área ocupada com cocais (SOLER et al., 2007). Neste mesmo sentido, Teixeira (2008) relata que oitenta por cento dos babaçuais se encontram no Maranhão, o maior Estado produtor, cuja produção representa quase $30 \%$ da produção brasileira de extrativos vegetais, empregando mais de dois milhões de pessoas. Mesmo com grande destaque na economia de estados da União, é uma cultura que necessita de maiores estudos na exploração de seu potencial, uma vez que seu aproveitamento econômico está ligado à extração e ao aproveitamento do óleo extraído da amêndoa, permanecendo o restante dos produtos apenas com riqueza potencial (TEIXEIRA, 2008). Entretanto, dado o sabor exótico e o reconhecido valor nutricional, a amêndoa de babaçu pode alcançar um lugar de destaque, aumentar seu consumo e mesmo incorporar-se ao cotidiano alimentar da população brasileira na forma de novos produtos alimentícios industrializados, como leite, farinha e iogurte de babaçu. Dentre estes produtos, o leite de babaçu é um subproduto do fruto que vem destacando-se na culinária local com reconhecimento regional; no entanto, estudos como os realizados no coco da Bahia (Cocos nucifera L.), são quase inexistentes (SOLER et al., 2007). O leite de babaçu, como o leite de coco, enquadra-se na categoria dos produtos denominados de baixa acidez, por apresentar $\mathrm{pH}$ final superior a 4,6 e atividade de água superior a 0,85 . Devido a estas características, é um bom substrato para o desenvolvimento de microrganismos de importância quanto aos aspectos industriais e de saúde pública, inclusive com possibilidade de desenvolvimento de bactérias patogênicas como o Clostridium botulinum. Assim, o processo de conservação industrialmente seguro para esse produto não deve basear-se apenas no emprego de uma pasteurização, ainda que se faça uso de conservantes químicos, como tem ocorrido até o presente. A pasteurização tem como objetivo principal a destruição de células vegetativas de microrganismos, sendo, consequentemente, um processamento térmico pouco efetivo no controle da deterioração por bactérias esporogênicas como o Clostridium botulinum. Por essa razão, os produtos pasteurizados demandam uma operação coadjuvante para prolongar sua estabilidade microbiológica, como, por exemplo: estocagem sob temperaturas reduzidas (refrigeração), ajuste do $\mathrm{pH}$ por acidificação com ácidos orgânicos, eliminação parcial de umidade, etc. (SEOW; GWEE, 1997). A conservação do leite de castanha-do-pará (Bertholettia excelsa) também foi pesquisada por Cardarelli e Oliveira (2000). O leite foi submetido a dois tratamentos (T1: 500 ppm de ácido, ésteres de metilpropil do ácido parahidrobenzoico, sorbato de potássio $0,2 \%$, e T2: $500 \mathrm{ppm}$ de ácido cítrico, 0,2 $\%$ de ácido benzoico e $0,2 \%$ de sorbato de potássio), embalados em sacos plásticos de náilon de polietileno e pasteurizados a $72,2^{\circ} \mathrm{C}$, por 20 minutos. Os leites pasteurizados foram armazenados sob refrigeração a $5{ }^{\circ} \mathrm{C}$. Os autores observaram que o emprego de pasteurização, refrigeração e adição de conservantes químicos garantiu a estabilidade físico-química e microbiológica do produto durante 180 dias de armazenamento. O objetivo desta pesquisa foi estudar a estabilidade de leite de babaçu baseado nos princípios de pasteurização e refrigeração.

\section{MATERIAIS E MÉTODOS}

Foram utilizadas amêndoas oriundas do Município de São Miguel do Tocantins. As amêndoas foram lavadas por imersão em água corrente, despeliculadas (retirada da película marrom que recobre a amêndoa) em descascador mecânico abrasivo, lavadas em água corrente e branqueadas com água a $80^{\circ} \mathrm{C}$, por 10 minutos. Após o branqueamento, as amêndoas foram desintegradas em liquidificador industrial, misturando-as com água a $80^{\circ} \mathrm{C}$, na proporção de 2 partes de água para 1 parte de amêndoa (v/p), até a obtenção de consistência homogênea, durante aproximadamente 15 minutos. A quantidade de água adicionada na homogeneização foi determinada conforme testes preliminares, sendo suficiente para obter um leite de babaçu padronizado com teor de gorduras de aproximadamente de 20 a 
$22 \%$ (leite de coco comercial). O homogeneizado foi alimentado à prensa de rosca sem fim (Finisher - extratora de leite de coco), provida de peneira com abertura de $0,45 \mathrm{~mm}$ de diâmetro, para a extração do leite de babaçu. Esse leite foi filtrado em tamis de 80 e 100 Mesh (ARUMUGHAN et al., 1993; SOLER et al., 2001), obtendo-se como produtos leite de babaçu e farinha úmida de babaçu. O leite de babaçu obtido foi pré-aquecido à temperatura de $85^{\circ} \mathrm{C}$, durante 15 minutos, sob agitação, até a coagulação de sua fração proteica. O leite coagulado foi homogeneizado em liquidificador durante 5 minutos, obtendo-se um produto de consistência fluida.

O leite foi então dividido em duas porções (formulações): na formulação A, foi adicionando, somente, o espessante carboximetilcelulose (CMC), na proporção de $0,15 \%$. Na segunda porção, formulação $\mathrm{B}$, foram adicionados $0,15 \%$ do carboximetilcelulose (CMC), 0,01\% de ácido cítrico, $0,04 \%$ de metabissulfito de sódio e $0,04 \%$ de sorbato de potássio, como conservantes. Os leites sem (formulação A) e com conservantes (formulação B) foram homogeneizados em liquidificador industrial por 5 minutos, envasados em garrafas de vidro de 200 mL com tampa metálica recravável e submetidos à pasteurização em banho-maria, à temperatura de $90^{\circ} \mathrm{C}$, por 30 minutos. Após atingirem a temperatura ambiente, foram mantidos sob refrigeração a $5^{\circ} \mathrm{C}$ (CARDARELLI ; OLIVEIRA, 2000), durante 60 dias. Os leites foram caracterizados físicoquimicamente quanto a umidade, gorduras, atividade de água, proteína, cinzas, acidez, pH, açúcares redutores e açúcares totais. A colorimetria foi determinada a $25^{\circ} \mathrm{C}$, usando um colorímetro digital (Minolta CR4000, fonte de luz D65 em espaço de cor L*a*b* do sistema CIE L*a*b), com calibração com placa branca padrão, seguindo as instruções do fabricante (KONICA MINOLTA, 2011). Os resultados foram expressos em $\mathbf{L} *$ (luminosidade) que varia de 0 (preto) a 100 (branco); o a* varia de $-\mathbf{a}^{*}$ (verde;) a $+\mathbf{a}^{*}$ (vermelho) e o b* de $-\mathbf{b}^{*}$ (azul) $\mathbf{a}+\mathbf{b}^{*}$ (amarelo). As análises microbiológicas foram realizadas quanto à presença de bolores e leveduras de acordo com a metodologia da APHA (VANDERZANT; SPLITTSTOESSER, 1992).

Para determinar-se a estabilidade ou a vida de prateleira dos produtos, a cada 15 dias, foram retiradas aleatoriamente duas amostras de cada formulação e submetidas a análises de $\mathrm{pH}$, acidez total titulável, atividade de água (Aw), colorimetria (Cie L*a*b*) e de contagem de bolores e leveduras. Os resultados foram avaliados por análise de variância e teste de Tukey, quando adequado, ao nível de significância de $5 \%$ de probabilidade $(p<0,05)$, utilizando o programa Statistica 5.0 for Windows.

\section{RESULTADOS E DISCUSSÃO}

Os resultados das análises físico-químicas das formulações A e B do leite de babaçu, realizadas logo após o processamento, encontram-se na Tabela 1, podendo-se observar que os componentes majoritários são a umidade e a gordura, variando de $75,40 \%$ a $76,11 \%$ e de $19,5 \%$ a $20,30 \%$, respectivamente. O teor de gordura apresentado está dentro do reportado por Soler et al. (1997) para leite de coco comercial, que varia de 19 a $29 \%$. O teor de proteínas variou de 2,45 a $2,70 \%$, e o de cinzas, de 0,22 a $0,27 \%$, enquanto o $\mathrm{pH}$ e os sólidos solúveis mostram valores de 6,64 a 6,80 e de 5 a $5^{\circ}$ Brix, respectivamente, valores que estão em concordância apresentados por Soler et al. (1985). Como se pode verificar, o leite de babaçu apresenta $\mathrm{pH}$ próximo à neutralidade e umidade superior a $75 \%$, portanto esse produto enquadra-se na categoria dos produtos denominados de baixa acidez, sendo um excelente meio para o desenvolvimento de microrganismos potencialmente perigosos à saúde pública, como o Clostridium botulinum. Este tipo de produto deve ser submetido a um tratamento térmico de esterilização ou à aplicação de métodos combinados de acidificação e pasteurização ou pasteurização e refrigeração, de forma que se mantenha estável microbiologicamente durante o armazenamento e seguro.

Para determinar a estabilidade físico-química e microbiológica das formulações do leite de babaçu, foram realizadas análises de $\mathrm{pH}$, acidez, atividade de água, bolores e leveduras e colorimetria, a cada 15 dias, durante os 60 dias de armazenamento, valores apresentadas nas Tabelas 2 e 3. Pode-se observar que os valores de $\mathrm{pH}$ e acidez variaram de 6,83 a 6,53 e 0,05 a 0,100 para a formulação A, e de 6,68 a 6,41 e 0,06 a 0,100 para a B. Estatisticamente, observaramse variações significativas nos valores de $\mathrm{pH}$ e acidez na formulação A, variações que podem ser atribuídas mais a problema de amostragem e homogeneidade da amostra do que ao armazenamento em si, já que não foi observada uma tendência de aumento ou redução desses parâmetros. Quanto à atividade de água, não foi verificada diferença significativa $(p<0,5)$, e os valores mantiveram-se praticamente constantes. Através dos valores das Tabelas 2 e 3, pode-se verificar que as duas formulações apresentaram altos valores de $\mathrm{L}^{*}\left(\mathrm{~L}^{*}>77\right)$, demonstrando que os leites de babaçu tendem para uma coloração branca, levemente amarelada ( $b^{*}$ positivo). Para as duas amostras, não houve alteração significativa $(\mathrm{p}<0,05)$ 
da cor durante o armazenamento. Nas Tabelas 2 e 3, estão apresentados os valores das análises microbiológicas (contagem de bolores e leveduras) realizadas nos leites de babaçu de formulação $\mathrm{A}$ e B, quando armazenadas durante os 60 dias sob refrigeração de $4{ }^{\circ} \mathrm{C}$. Os valores indicam crescimento de microrganismos a partir dos 30 dias na formulação A e após 45 dias na B, atingindo valores elevados, acima dos padrões microbiológicos estabelecidos pela legislação, após 60 dias de armazenamento. A legislação brasileira (BRASIL, 2001) estabelece uma tolerância de $10^{4} \mathrm{UFC} / \mathrm{g}$ para bolores e leveduras em alimentos como sucos e néctares de frutas que foram pasteurizados. Entretanto, na formulação B, apesar de o produto ter sido pasteurizado, envasado a quente $\mathrm{e}$ adicionado de conservantes químicos, também houve crescimento de microrganismos a partir dos 45 dias de armazenamento,alcançando valores elevados de $10^{5} \mathrm{UFC} / \mathrm{g}$ nos mesmos 60 dias da formulação A, que não recebeu os conservantes. Similares resultados foram reportados por Matietto et al. (2007) para néctar misto de umbu e cajá pasteurizado e envasado em garrafas de vidro. Segundo Seow e Gwee (1997), no leite de coco, por ser um produto rico em nutrientes, podem desenvolver-se diferentes tipos de microrganismos (bactérias, fungos, leveduras, etc.) que são usualmente introduzidos através da própria matéria-prima, dos utensílios, equipamentos de processo e dos manipuladores. Como o leite de babaçu é um produto muito semelhante ao leite de coco em composição e características organolépticas, pode ter acontecido contaminação da amostra em algum momento do processo, o que se reflete no crescimento microbiano durante o armazenamento, mesmo sob refrigeração. O leite de coco pasteurizado, embalado em sacos plásticos e armazenado sob refrigeração a $4{ }^{\circ} \mathrm{C}$, apresenta uma vida de prateleira de apenas 5 dias (SEOW; GWEE, 1997).

TABELA 1- Análises físicas e químicas do leite de coco de babaçu.

\begin{tabular}{lcc}
\hline \multirow{2}{*}{ Análises } & \multicolumn{2}{c}{ Resultados analíticos } \\
\cline { 2 - 3 } & Formulação A & Formulação B \\
\hline $\mathrm{pH}$ & $6,80 \pm 0,03$ & $6,64 \pm 0,01$ \\
Sólidos solúveis ( ${ }^{\circ}$ Brix) & $5,0 \pm 0,03$ & $5,0 \pm 0,04$ \\
Acidez total titulável (\%) & $0,072 \pm 0,001$ & $0,109 \pm 0,002$ \\
Açúcares redutores (\%) & $0,0011 \pm 0,0002$ & $0,0008 \pm 0,0001$ \\
Açúcares totais (\%) & $0,0013 \pm 0,004$ & $0,0015 \pm 0,0003$ \\
Umidade (\%) & $75,40 \pm 0,03$ & $76,11 \pm 0,02$ \\
Cinzas (\%) & $0,27 \pm 0,01$ & $0,22 \pm 0,04$ \\
Gordura (\%) & $20,30 \pm 0,04$ & $19,50 \pm 0,03$ \\
Proteína (\%) & $2,45 \pm 0,05$ & $2,70 \pm 0,03$ \\
\hline
\end{tabular}

TABELA 2-Análises físico-químicas e microbiológicas do leite de babaçu - Formulação A.

\begin{tabular}{lccccc}
\hline \multirow{2}{*}{ Análises } & \multicolumn{5}{c}{ Tempo (dias) } \\
\cline { 2 - 6 } $\mathrm{pH}$ & $6,80 \mathrm{a}$ & $6,83 \mathrm{a}$ & $6,63 \mathrm{a}$ & $6,53 \mathrm{~b}$ & $6,80 \mathrm{a}$ \\
Acidez & $0,07 \mathrm{a}$ & $0,05 \mathrm{~b}$ & $0,100 \mathrm{a}$ & $0,09 \mathrm{a}$ & $0,075 \mathrm{a}$ \\
$\mathrm{Aw}$ & $0,970 \mathrm{a}$ & $0,970 \mathrm{a}$ & $0,978 \mathrm{a}$ & $0,982 \mathrm{a}$ & $0,980 \mathrm{a}$ \\
${ }^{\circ}$ Brix & 5,0 & 5,0 & 4,98 & 4,98 & 4,97 \\
Açúcares totais (\%) & 0,0013 & 0,0013 & 0,0012 & 0,0011 & 0,0010 \\
\hline Cor: & & & & & \\
\multicolumn{1}{c}{$\mathrm{L}^{*}$} & $78,68 \mathrm{a}$ & $77,84 \mathrm{a}$ & $76,98 \mathrm{a}$ & $77,21 \mathrm{a}$ & $77,10 \mathrm{a}$ \\
\multicolumn{1}{c}{$\mathrm{a}^{*}$} & $-0,30 \mathrm{a}$ & $-0,23 \mathrm{a}$ & $-0,10 \mathrm{~b}$ & $-0,19 \mathrm{c}$ & $-0,15 \mathrm{c}$ \\
$\quad \mathrm{b}^{*}$ & $2,04 \mathrm{a}$ & $1,82 \mathrm{~b}$ & $1,56 \mathrm{c}$ & $1,60 \mathrm{c}$ & $1,89 \mathrm{~b}$ \\
\hline Bolores e leveduras & Ausente & Ausente & $1,0 \times 10^{2}$ & $1,0 \times 10^{3}$ & $1,4 \times 10^{5}$ \\
(UFC/mL) & & & & & \\
\hline
\end{tabular}

Letras iguais na mesma linha significam que não há diferenças significativas entre os diferentes tempos de armazenamento (ao nível de $5 \%$ de probabilidade, pelo teste de Tukey, $\mathrm{p}<0,05)$. 
TABELA 3-Análises físico-químicas e microbiológicas do leite de babaçu - formulação B.

\begin{tabular}{lccccc}
\hline \multirow{2}{*}{ Análises } & \multicolumn{5}{c}{ Tempo (dias) } \\
\cline { 2 - 6 } pH & $0,64 \mathrm{a}$ & $6,68 \mathrm{a}$ & $6,42 \mathrm{a}$ & $6,41 \mathrm{a}$ & $6,70 \mathrm{a}$ \\
Acidez & $0,10 \mathrm{a}$ & $0,07 \mathrm{a}$ & $0,06 \mathrm{a}$ & $0,06 \mathrm{a}$ & $0,062 \mathrm{a}$ \\
$\mathrm{Aw}$ & $0,98 \mathrm{a}$ & $0,97 \mathrm{a}$ & $0,98 \mathrm{a}$ & $0,98 \mathrm{a}$ & $0,98 \mathrm{a}$ \\
${ }^{\circ} \mathrm{Brix}$ & 5,0 & 4,98 & 4,98 & 4,97 & 4,96 \\
Açúcares totais (\%) & 0,0015 & 0,0014 & 0,0014 & 0,0013 & 0,0013 \\
\hline Cor: & & & & & \\
\multicolumn{1}{c}{$\mathrm{L}^{*}$} & $79,42 \mathrm{a}$ & $79,48 \mathrm{a}$ & $78,01 \mathrm{a}$ & $78,78 \mathrm{a}$ & $78,87 \mathrm{a}$ \\
\multicolumn{1}{c}{$\mathrm{a}^{*}$} & $-0,51 \mathrm{a}$ & $-0,45 \mathrm{a}$ & $-0,50 \mathrm{a}$ & $-0,37 \mathrm{~b}$ & $-0,39 \mathrm{~b}$ \\
$\quad \mathrm{~b}^{*}$ & $2,37 \mathrm{a}$ & $2,36 \mathrm{a}$ & $1,87 \mathrm{~b}$ & $2,13 \mathrm{a}$ & $2,20 \mathrm{a}$ \\
\hline $\begin{array}{l}\text { Bolores e leveduras } \\
\text { (UFC/ml) }\end{array}$ & Ausente & Ausente & Ausente & $1,0 \times 10^{2}$ & $1,5 \times 10^{5}$
\end{tabular}

Letras iguais na mesma linha significam que não há diferenças significativas entre os diferentes tempos de armazenamento (ao nível de $5 \%$ de probabilidade, pelo teste de Tukey, $\mathrm{p}<0,05)$.

\section{CONCLUSÕES}

A tecnologia de conservação do leite de coco de babaçu por métodos combinados de pasteurização e refrigeração mostrou-se viável por 45 dias, em escala de laboratório, o que representa um avanço tecnológico importante para industrialização e colocação no mercado deste produto. No leite processado, tanto com, como sem conservantes, não se observaram mudanças significativas da cor durante $\mathrm{o}$ armazenamento.

\section{REFERÊNCIAS}

ARUMUGHAN, C.; BALACHANDRAN, C.; SUNDARESAN, A. Development of a process for coconut cream on comercial scale. Journal of Food Science and Technology, Mysore, v 30, p. 408-412, 1983.

BRASIL. Resolução RDC n 12 , de 02 de janeiro de 2001, da Agência Nacional de Vigilância Sanitária. Regulamento Técnico sobre Padrões microbiológicos para Alimentos. Diário Oficial da República Federativa do Brasil, Brasília-DF, 10 jan. 2001. Seção 1, p.45-53.

CARDARELLI, H. R.; OLIVEIRA, A. J. Conservação de castanha-do-pará. Scientia Agrícola, Piracicaba, v. 57, n. 4, p. 617-622, 2000.

KONICA MINOLTA. Chromameter CR-400 instruction manual. Sakai: Ed. Konica Minolta, 2011.
MATIETTO, R. A.; LOPES, A. S.; MENEZES, H. C. Estabilidade do néctar misto de cajá e umbu. Ciência e Tecnologia de Alimentos, Campinas, v. 27, n. 3, p. 456-463, 2007.

SEOW, C.C.; GWEE, C.N. Review, coconut milk: chemistry and technology. International Journal of Science and Technology, Oxford, v.32, p.189201, 1997.

SOLER, M. P.; VITALI, A. A.; MUTO, E. F. Tecnologia de quebra de coco babaçu (Orbygnia speciosa). Ciência e Tecnologia de Alimentos, Campinas, v. 27, n. 4, 2007.

SOLER, M. P.; VITALI, A. A. Aplicação de hidrocoloides na estabilidade de emulsões simuladas do leite de coco. Brazilian Journal of Food technology,v.4, n.59, p.57-66, 2001.

TEIXEIRA, M.A. Babassu - A new approach for an ancient Brazilian biomass. Biomass \& Bioenergy, Oxford, v.32, n.9, p.857-864, 2008.

VANDERZANT, T.; SPLITTSTOESSER, E. F. Compendium of methods for the microbiological examination of foods. $3^{\text {rd }}$ ed. Washington: American Public Health Association, 1992. 1919 p. 